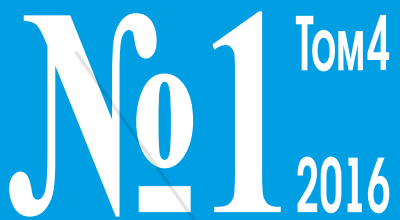

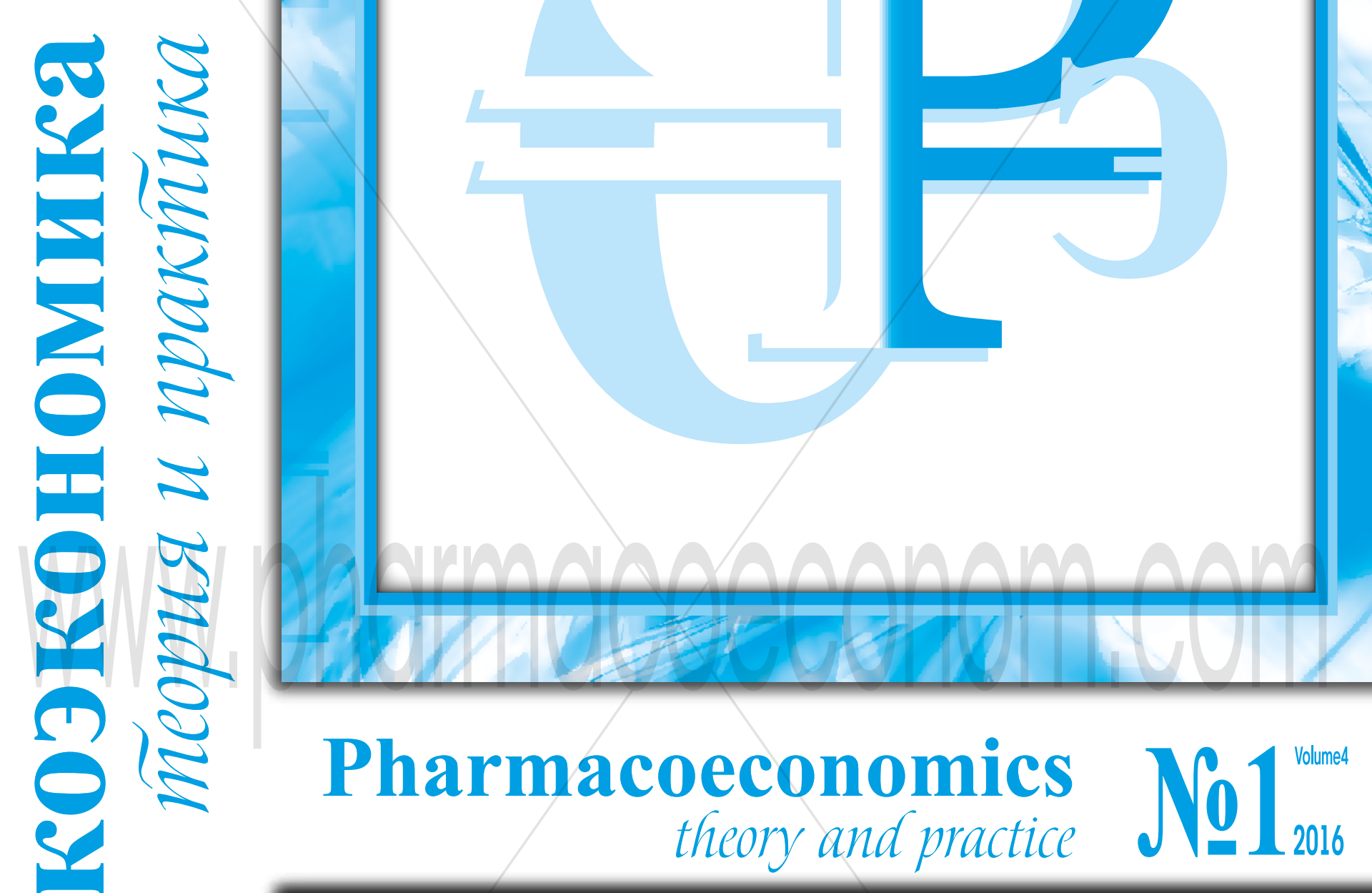

$\square$ МЕТОДОЛОГИЧЕСКИЕ ОСНОВЫ ФАРМАКОЭКОНОМИЧЕСКОГО МОДЕЛИРОВАНИЯ

$\square$ РЕЗУЛЬТАТЫ РОССИЙСКИХ ФАРМАКОЭКОНОМИЧЕСКИХ ИССЛЕДОВАНИЙ

口 МАТЕРИАЛЫ Х НАЦИОНАЛЬНОГО КОНГРЕССА С МЕЖДУНАРОДНЫМ УЧАСТИЕМ «РАЗВИТИЕ ФАРМАКОЭКОНОМИКИ И ФАРМАКОЭПИДЕМИОЛОГИИ В РОССИЙСКОЙ ФЕДЕРАЦИИ» 4-5 апреля 2016 г., г. Нижний Новгород 


\title{
ИНСУЛИНОТЕРАПИЯ САХАРНОГО ДИАБЕТА 2 ТИПА У ПАЦИЕНТОВ С АРТЕРИАЛЬНОЙ ГИПЕРТОНИЕЙ
}

\section{INSULINOTHERAPY OF DIABETES MELLITUS IN PATIENTS WITH HYPERTENSION}

\author{
Черная Е.В., Рыженкова И.Г., Ардентова Н.Н. \\ Chernaya E.V., Ryzhenkova I.G., Ardentova N.N.
}

\author{
ГБОУ ВПО Саратовский ГМУ им. В.И. Разумовского Минздрава России, г.Саратов \\ Saratov State Medical University named after V.I. Razumovsky, Saratov
}

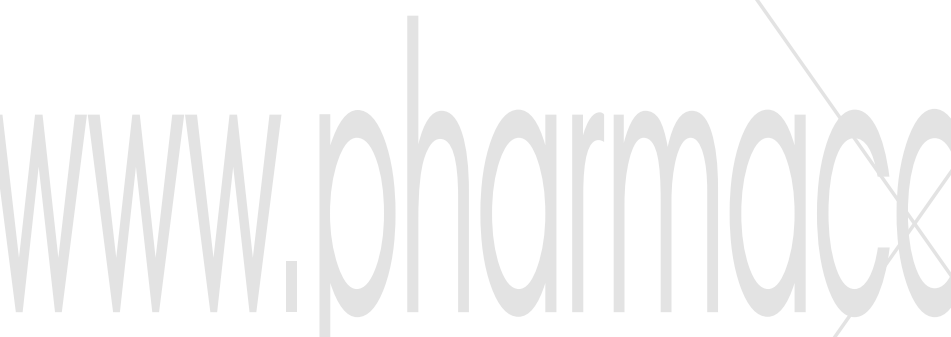

Ключевые слова: фармакоэпидемиологический анализ, сахароснижающая терапия.

Введение: сахарный диабет 2 типа (СД 2 типа) - неуклонно прогрессирующее заболевание. Гиперинсулинизм, свойственный началу заболевания, постепенно сменяется дефицитом инсулина, обусловленным снижением остаточной секреции $\beta$-клеток, пациент начинает нуждаться в инсулинотерапии. По данным проспективного исследования диабета (UKPDS), ежегодно 5-10\% больных со впервые диагностированным СД 2 типа требуется терапия инсулином, а спустя 10-12 лет - уже около 80\% пациентов нуждаются в постоянной инсулинотерапии. В настоящее время в развитых странах около 30-40 \% всех больных СД 2 типа получают инсулин. Значимым фактором, усиливающим инсулинорезистентность и ускоряющим наступление истощения функции поджелудочной железы, является артериальная гипертензия (АГ).

Цель исследования: оценить структуру назначения препаратов инсулина и степень компенсации углеводного обмена у пациентов с СД 2 типа и АГ, получающих инсулинотерапию в амбулаторной практике в 2011-2012гг.

Материалы и методы: проведено фармакоэпидемиологическое исследование, основанное на анализе амбулаторных карт пациентов формы №025/y-04. Ретроспективно оценивались амбулаторные карты пациентов, имеющих установленный диагноз СД 2 типа и АГ, наблюдавшихся в поликлиниках г. Саратова с января 2011г по декабрь 2012г, обратившихся в поликлинику не менее 2-х раз в год. Оценка карт произведена сплошным методом. В специально разработанную индивидуальную регистрационную карту заносились данные амбулаторных карт. Учитывались только письменно зафиксированные в карте назначения.

Результаты: в ходе исследования были проанализированы 250 историй болезней пациентов с диагнозом СД 2 типа и АГ за 2011-2012гг. Анализ сахароснижающей терапии показал, что монотерапию инсулином получали $15,2 \%$ больных, комбинированную терапию инсулином и таблетированными сахароснижающими препаратами (ТССП) получали 2,8\% от общего числа больных, остальные пациенты получали лечение только ТССП. В группе пациентов, получавших монотерапию инсулином, 91,2\% больных получали базис-болюсную терапию инсулинами короткого и ультракороткого действия в сочетании с инсулином продленного действия, а 8,8\% пациентов получали лечение комбинированными препаратами аналогов инсулина, представляющих собой смесь ультракороткого и пролонгированного инсулина в фиксированном соотношении. При анализе группы пациентов, получающих комбинированное лечение инсулином и ТССП, выяснено, что лечение препаратами сульфонилмочевины в сочетании с инсулином продленного действия получают $71,4 \%$ из общего числа больных указанной группы, а лечение инсулином в сочетании с метсормином - 28,6\% пациентов этой группы. В связи с тем, что сочетание СД 2 типа и АГ входит в структуру метаболического синдрома, связанного с инсулинорезистентностью, препаратом выбора, при отсутствии противопоказаний, является метформин.

Для оценки степени компенсации углеводного обмена у пациентов, получавших инсулин, проведен анализ уровня гликированного гемоглобина (HbA1) , как основного показателя эффрективности проводимой терапии и оценки рисков формирования сосудистых осложнений. Выяснено, что уровень НbA1 определен дважды за год у $2 \%$ пациентов, 1 раз в год - у 46,7 \% пациентов, у оставшихся 51,3 \% не исследован ни разу за период наблюдения. В группе тех пациентов, которым исследован уровень НbA1, адекватный контроль сахарного диабета имели лишь $13 \%$ от общего числа больных.

Заключение: результаты проведенного исследования свидетельствуют о неудовлетворительной метаболической компенсации диабета, даже на фоне инсулинотерапии у больных с СД 2 типа и АГ. Полученный процент больных, получающих инсулин значительно ниже среднестатистического, что вероятно свидетельствует о позднем начале инсулинотерапии. Недостаточно часто в комбинации с инсулином используется метформин, являющийся средством патогенетической терапии пациентов с СД 2 типа и АГ. 